\title{
COnE).(OES
}

CIÊNCIA E TECNOLOGIA

\section{PROGRAMA NACIONAL DO LIVRO E DO MATERIAL DIDÁTICO (PNLD): UM ESTUDO DE SEU FUNCIONAMENTO E APRESENTAÇÃO DAS MUDANÇAS NOS MATERIAIS À LUZ DO NOVO ENSINO MÉDIO A PARTIR DE 2021}

\author{
Natalia da Silva Fernandes, Francisco Herbert Lima Vasconcelos, \\ WINDSON VIANA DE CARVALHO \\ Universidade Federal do Ceará - UFC \\ <natysilvafernandes@gmail.com>.<herbert@virtual.ufc.br>,<windcarvalho@gmail.com> \\ DOI: 10.21439/conexoes.v15i0.2099
}

\begin{abstract}
Resumo. O artigo descreve o Programa Nacional do Livro e do Material Didático (PNLD), uma das mais antigas políticas públicas do Brasil, quanto ao seu funcionamento para o Ensino Médio (EM) desde o seu surgimento, e relata as mudanças, que estão previstas com base na Lei do Novo Ensino Médio (13.415/17), dos materiais didáticos para 2021 através de uma revisão bibliográfica dos principais marcos legais educacionais nas bases de dados Google Scholar e SciELO Brasil, como também em documentos que norteiam a educação. A leitura aponta para uma das maiores mudanças ocorridas no PNLD dos últimos 20 (vinte) anos, que passará a contemplar obras e materiais didáticos que proporcionem ao aluno uma trajetória escolar transformadora, pautada no desenvolvimento de competências e habilidades que o capacitem para lidar com os desafios da sociedade em que o mesmo está inserido, ou seja, objetivam o fortalecimento do protagonismo juvenil.
\end{abstract}

Palavras-chaves: Políticas públicas. PNLD. Contextualização histórica. Novo Ensino Médio. Materiais Didáticos.

\section{NATIONAL PROGRAM FOR BOOK AND TEACHING MATERIAL (PNLD): A STUDY OF ITS OPERATION AND PRESENTATION OF CHANGES IN MATERIALS IN THE LIGHT OF THE NEW HIGH SCHOOL FROM 2021}

\begin{abstract}
The article describes the National Program of Book and Didactic Material (PNLD), one of the oldest public policies in Brazil, regarding its functioning for Secondary Education (EM) since its emergence, and reports the changes, which are foreseen with based on the New High School Law (13.415/17), the teaching materials for 2021 through a bibliographic review of the main educational legal frameworks in the Google Scholar and SciELO Brazil database, as well as in documents that guide education. The reading points to one of the biggest changes that occurred in the PNLD of the last 20 (twenty) years, which will include works and courseware that provide to the student, a transformative school trajectory, based on the development of skills and abilities that enable him to deal with challenges of the society in which is inserted, i.e., they aim at strengthening youth protagonism.
\end{abstract}

Keywords: Public policy. PNLD. Historical contextualization. New High School. Courseware.

\section{INTRODUÇÃO}

De acordo com Santos (2012), política pública pode ser entendida como uma ação geradora na esfera do Estado que objetiva atingir a sociedade como um todo ou partes dela. Assim, as políticas públicas são elementos de grande importância para a constituição das políticas educacionais.

Ainda segundo Santos (2012, p. 3, grifos do autor),

[...]política educacional corresponde a: toda e qualquer política desenvolvida de modo a intervir nos processos formativos (e informativos) desenvolvidos em sociedade (seja na instância coletiva, seja na instância individual) e, por meio dessa intervenção, legitima, constrói 
PROGRAMA NACIONAL DO LIVRO E DO MATERIAL DIDÁTICO (PNLD): UM ESTUDO DE SEU FUNCIONAMENTO E APRESENTAÇÃO DAS MUDANÇAS NOS MATERIAIS À LUZ DO NOVO ENSINO MÉDIO A PARTIR DE 2021

ou desqualifica (muitas vezes de modo indireto) determinado projeto político, visando a atingir determinada sociedade

Nesse contexto, o Programa Nacional do Livro e do Material Didático (PNLD) surgiu como uma forma de subsidiar a política educacional implantada pelo estado brasileiro com objetivo de cumprir o direito de acesso à Educação Básica (EB) à população. Direito esse que é assegurado pelo artigo 205 da Constituição Federal de $1988(\mathrm{CF} / 88)$ :

\begin{abstract}
A educação, direito de todos e dever do Estado e da família, será promovida e incentivada com a colaboração da sociedade, visando ao pleno desenvolvimento da pessoa, seu preparo para o exercício da cidadania e sua qualificação para o trabalho.
\end{abstract}

Mas não basta apenas garantir o acesso à educação, é preciso fornecer condições mínimas para que ela aconteça. O artigo 208 da CF/88 estabelece que:

O dever do Estado com a educação será efetivado mediante a garantia de (...) VII - atendimento ao educando no ensino fundamental através de programas suplementares de material didático-escolar, transporte, alimentação e assistência à saúde.

Assim, o Estado tem o dever de garantir ao educando o ensino básico e criar programas suplementares que deem assistência ao aluno, fornecendo, por exemplo, de forma gratuita e obrigatória o livro didático (LD), objeto que representa, na educação brasileira, o material mais utilizado em salas de aula das instituições de ensino básico, embora não seja o único (FREITAS; RODRIGUES, 2019). O acesso ao LD é um direito do aluno da EB no Brasil, garantido por diversos dispositivos legais, como a Lei de Diretrizes e Bases da Educação Nacional (LDB) e vários outros decretos, portarias e resoluções do Ministério da Educação (MEC).

E para garantir o acesso a esse material que é de suma importância nas escolas, pois auxilia os professores no processo de ensino e aprendizagem, surge o PNLD. Este é um dos programas mais antigos na esfera pública de ensino do Brasil e que também já sofreu mais mudanças desde a sua criação. Desde 1996, a compra de LD está subordinada ao PNLD, com a preocupação de garantir a qualidade dos livros. A oferta do LD se insere na tentativa de melhorar a educação nacional como um todo (ZAMBON; TERRAZZAN, 2013). Atualmente tem por objetivo distribuir de forma sistemática e regular LDs às escolas públicas de Ensino Fundamental (EF) e Ensino Médio (EM), bem como também distribuir outros materiais que auxiliam o trabalho pedagógico dos professores (BRASIL, 2017a).
Com o surgimento desse programa e o aperfeiçoamento de seus critérios de seleção de materiais didáticos ao longo dos anos, percebem-se mudanças tanto na elaboração quanto na forma de uso desses recursos pedagógicos. E uma das mudanças mais significativas acontece com a implementação da Lei 13.415/2017, que busca tornar o EM, etapa escolar que concentra os piores resultados de aprendizagem e os maiores índices de evasão de estudantes, mais atraente e mais próxima à realidade dos alunos (IBGE, 2016). Consequentemente, o PNLD passa por transformações com a missão de se adequar à nova proposta para a educação brasileira quanto ao Novo Ensino Médio.

Sendo assim, o presente artigo tem como objetivo principal investigar os impactos da Lei 13.415/2017 nas obras do PNLD do EM, através de uma revisão bibliográfica nas bases de dados Google Scholar e SciELO Brasil, bem como busca também responder aos questionamentos: quais parâmetros devem ser utilizados pelas editoras para elaboração dos objetos didáticos, como serão organizados e distribuídos frente a essas mudanças e como contribuirão para a formação do público alvo.

Este trabalho está dividido em 6 seções, além desta introdução. A seção 2 expõe revisão de literatura sobre a contextualização histórica e sobre o funcionamento do PNLD para o EM antes da reforma. Na seção 3 são relatadas as mudanças ocorridas no PNLD do EM à luz do decreto no 9099/2017. A seção 4 apresenta a metodologia utilizada. Análise e discussão dos resultados são apresentados na seção 5. Por fim, na seção 6 são feitas as considerações finais.

\section{BREVE HISTÓRICO DO PNLD PARA O EM E SEU FUNCIONAMENTO ANTES DA IMPLE- MENTAÇÃO DO NOVO ENSINO MÉDIO}

O PNLD é um programa do Governo Federal do Brasil que tem por objetivo conduzir o processo de produção, avaliação e distribuição de obras didáticas, pedagógicas literárias, bem como outros instrumentos que servirão de suporte ao processo de ensino-aprendizagem no âmbito escolar. Esses materiais são destinados a docentes e discentes das escolas públicas de EB, de instituições comunitárias, confessionais ou filantrópicas sem fins lucrativos e conveniadas com o Poder Público (FNDE, 2021a). De acordo com o programa, cada aluno tem direito a um volume das disciplinas que serão estudadas durante o ano letivo.

O PNLD envolve várias outras esferas: o MEC, que é responsável pelas etapas operacionais, e o Fundo Nacional de Desenvolvimento da Educação (FNDE), que administra os recursos financeiros, bem como a defi- 
PROGRAMA NACIONAL DO LIVRO E DO MATERIAL DIDÁTICO (PNLD): UM ESTUDO DE SEU FUNCIONAMENTO E APRESENTAÇÃO DAS MUDANÇAS NOS MATERIAIS À LUZ DO NOVO ENSINO MÉDIO A PARTIR DE 2021

nição dos valores repassados às editoras (THADEU, 2019).

Como já citado anteriormente, o PNLD é o programa de estado, no âmbito das políticas educacionais, mais antigo do Brasil. DI GIORGI et al. (2014) afirma que esse programa foi modificado diversas vezes, adquirindo diferentes nomenclaturas e formatos de funcionamento. Segundo Bragança (2009), seu surgimento pode ser associado à criação do Instituto Nacional do Livro (INL) - 1937 a 1990 - quando tardiamente o Estado brasileiro começou a desenvolver políticas públicas voltadas ao LD no país. O surgimento do instituto ocorreu no governo de Getúlio Vargas (1930-1945) por iniciativa do então ministro da Educação e Saúde Pública, Gustavo Capanema. O INL objetivava elaborar uma enciclopédia brasileira e um dicionário da língua, que iriam servir de base para a formação cultural da população, e também expandir a quantidade de bibliotecas públicas.

As primeiras ações para motivar o aparecimento de um programa voltado para escolha de materiais didáticos remontam ao ano de 1938, com o surgimento da Comissão Nacional do Livro Didático (CNLD), através do Decreto-Lei no 1.006/1938. A partir daí, o Estado define sua primeira política de legislação e controle de produção e distribuição do LD no Brasil (FNDE, 2021b).

Após a criação de inúmeros decretos e leis, Freitas e Rodrigues (2019) relatam que o atual PNLD veio em substituição ao antigo Programa do Livro Didático para o Ensino Fundamental (PLIDEF), em 1985, com a reformulação do decreto $\mathrm{n}^{\circ} 91.542 / 1985$, objetivando promover a redemocratização do país através da universalização e melhoria da EB. Entretanto, o programa não atendia a todos os alunos nem todas as disciplinas uma vez que não havia uma regra de regulamentação de compra e distribuição do material.

O novo programa do LD trouxe mudanças significativas em relação ao antigo. Dentre elas, Cassiano (2004) aponta as seguintes:

\section{a) o término da compra do livro descartável, ou seja, o governo não compraria mais livros que contivessem exer- cícios para serem feitos no próprio livro, para possibilitar a sua reutilização por outros alunos em anos posteriores Sendo assim, o governo passou a comprar somente livros não-consumíveis; b) a escolha do livro didático passou a ser feita diretamente pelo professor; c) distribuição gra- tuita às escolas públicas e sua aquisição com recursos do Governo Federal (CASSIANO 2004 p. 3).}

O processo de avaliação pedagógica dos livros que concorrem para o PNLD foi iniciado em 1996, ano em que a distribuição passou a ser nacional, e já foram realizadas várias modificações. Para a escolha dos materiais o MEC publicou o primeiro "Guia de Livros Didá- ticos $\left(1^{\mathrm{a}}\right.$ a $4^{\mathrm{a}}$ série)", instrumento que traz a resenha das obras aprovadas, após um criterioso processo de avaliação realizado em parceria com Universidades públicas, que poderão ser escolhidas pelos professores e usadas durante três anos. De acordo com Thadeu (2019), nesse mesmo ano, o programa se fortaleceu quanto às regularizações, visto que a avaliação dos livros ficou mais rigorosa e criteriosa e a distribuição passou a seguir regras e leis. Com isso, segundo Rosa (2017), os materiais didáticos passaram a ter uma qualidade melhor, uma vez que, para concorrer ao PNLD, as editoras precisaram reformular suas obras para se tornarem adequadas às exigências do programa.

Segundo Maciel (2014, p. 234), no ano de 2000, o programa aumentou sua capacidade de aquisição e distribuição de LD, o que lhe conferiu em 2001 um registro no Guinness Book por ser considerado o maior programa de avaliação e distribuição LDs do mundo.

Apenas no ano de 2003, com a publicação da Resolução/CD/FNDE no. 38/2003, surge o Programa Nacional do Livro Didático para o Ensino Médio (PNLEM), que objetivava prover às escolas públicas do EM LDs de qualidade englobando os componentes curriculares de Português e Matemática. O PNLEM foi implantado de forma progressiva a partir de 2004 (FNDE, 2021b).

A partir de 2009, algumas regras mudaram no PNLD e se tornaram mais consolidadas. Uma delas foi que as escolas públicas deveriam manifestar interesse em participar do PNLD, conforme Resolução CD FNDE, n. ${ }^{\circ}$ 60/2009, para, assim, se seguirem as etapas apresentadas na Figura 1 .

Em 2010, o PNLD se consolida como uma Política Educacional Brasileira e suas atribuições e normas de funcionamento ficam asseguradas através do Decreto n. ${ }^{\circ} 7.084 / 2012$. Nesse mesmo ano, aconteceu a primeira reposição e complementação de LDs para o EM, que passaram a ser adquiridos e distribuídos integralmente a partir de 2011 .

\section{O QUE MUDA NO PNLD DO EM A PARTIR DA LEI №13.415/2017}

No ano de 2017 várias mudanças ocorrem no cenário da educação pública brasileira. Inicialmente, em fevereiro, a Lei $n^{\circ}$ 13.415/2017 altera a LDB no 9394/1996 e passa a estabelecer uma mudança na estrutura do EM, ampliando o tempo mínimo do estudante na escola de 800 para 1.000 horas anuais, que deve acontecer gradativamente até 2022, e definindo um novo currículo que contemple a Base Nacional Comum Curricular (BNCC), homologada em 14 de dez. de 2018. Outra alteração é que os alunos poderão escolher os itinerários formativos (o que hoje equivale às disciplinas) com 
PROGRAMA NACIONAL DO LIVRO E DO MATERIAL DIDÁTICO (PNLD): UM ESTUDO DE SEU FUNCIONAMENTO E APRESENTAÇÃO DAS MUDANÇAS NOS MATERIAIS À LUZ DO NOVO ENSINO MÉDIO A PARTIR DE 2021

Figura 1: Mapa conceitual elaborado para explicar o funcionamento do PNLD.

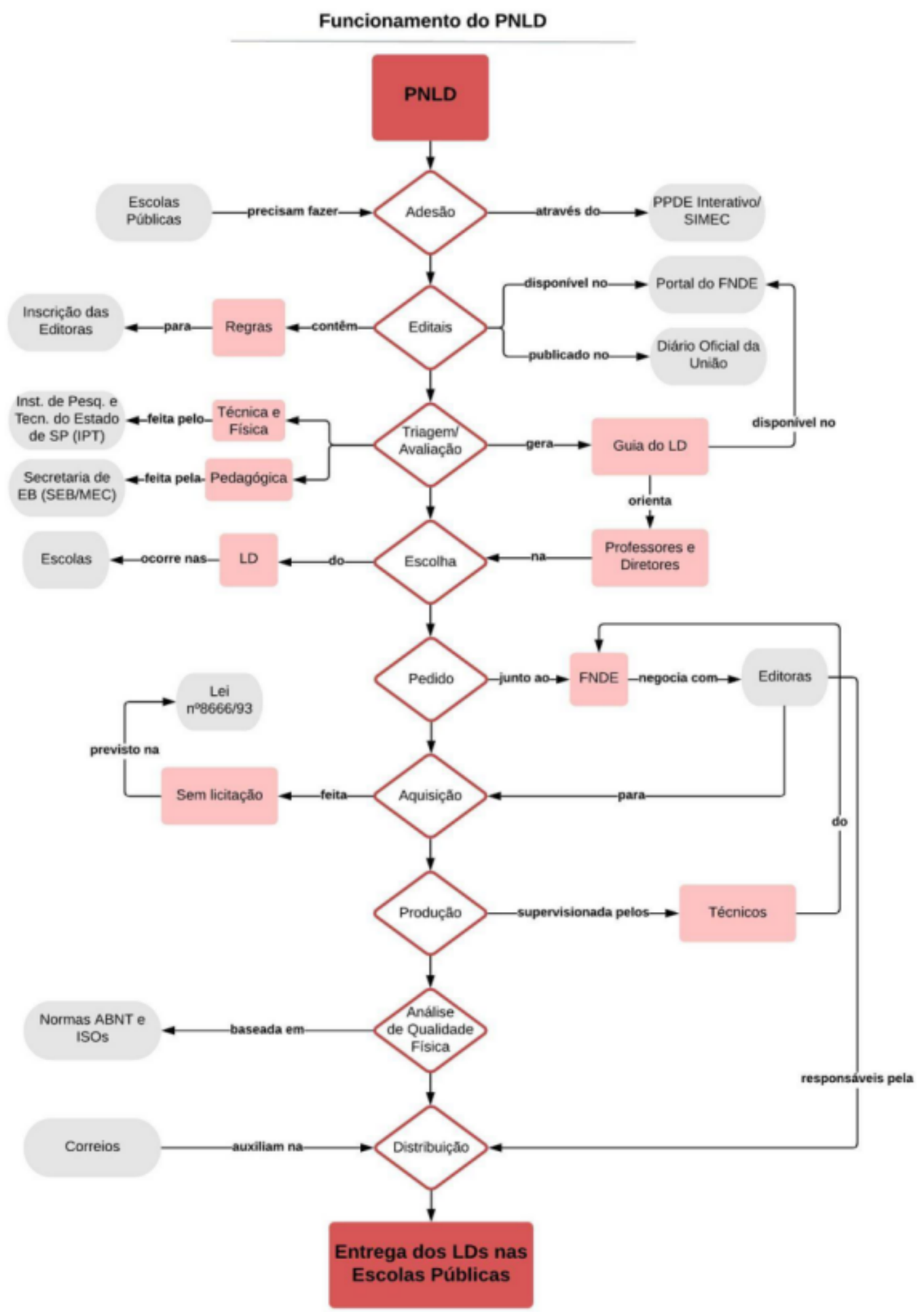

Fonte: Elaborada pelos autores com base em informações levantadas na página do FNDE (2021a). 
PROGRAMA NACIONAL DO LIVRO E DO MATERIAL DIDÁTICO (PNLD): UM ESTUDO DE SEU FUNCIONAMENTO E APRESENTAÇÃO DAS MUDANÇAS NOS MATERIAIS À LUZ DO NOVO ENSINO MÉDIO A PARTIR DE 2021

base nas suas afinidades e escolha profissional.

O Art. 35-A da Lei, $n^{\circ} 13.415 / 2017$ traz a seguinte redação:

$\S 7$ o Os currículos do ensino médio deverão considerar a formação integral do aluno, de maneira a adotar um trabalho voltado para a construção de seu projeto de vida e para sua formação nos aspectos físicos, cognitivos e socioemocionais (BRASIL, 2017c).

No Art. 4 da mesma lei, há a modificação do texto do Art. 36 da Lei no 9.394/1996, passando a valer a seguinte orientação:

Art. 36. O currículo do ensino médio será composto pela Base Nacional Comum Curricular e por itinerários formativos, que deverão ser organizados por meio da oferta de diferentes arranjos curriculares, conforme a relevância para o contexto local e a possibilidade dos sistemas de ensino, a saber: I - linguagens e suas tecnologias; II - matemática e suas tecnologias; III - ciências da natureza e suas tecnologias; IV - ciências humanas e sociais aplicadas; V - formação técnica e profissional (BRASIL. 2017c).

Também se torna obrigatório estudos e práticas de Educação Física, Arte, Sociologia e Filosofia, conforme Art. 35-A, $\S 2^{\circ}$ da referida lei, bem como também o ensino de língua portuguesa e matemática será obrigatório nos três anos do ensino médio. A mesma lei torna o Inglês obrigatório desde o $6^{\circ}$ ano do EF até o EM.

No mesmo ano, estabeleceu-se o Decreto ${ }^{\circ}$ 9.099, que unificou as ações anteriormente contempladas pelo PNLD e pelo Programa Nacional Biblioteca da Escola (PNBE). O Decreto ${ }^{\circ}$ 9099/2017 revoga o decreto $n^{\circ}$ 7084/2010 e os objetivos do PNLD, segundo o Art. $2^{\circ}$, passam a ser:

\footnotetext{
I - aprimorar o processo de ensino e aprendizagem nas escolas públicas de educação básica, com a consequente melhoria da qualidade da educação; II - garantir o padrão de qualidade do material de apoio à prática educativa utilizado nas escolas públicas de educação básica; III - democratizar o acesso às fontes de informação e cultura; IV - fomentar a leitura e o estímulo à atitude investigativa dos estudantes; V - apoiar a atualização, a autonomia e o desenvolvimento profissional do professor; e VI - apoiar a implementação da Base Nacional Comum Curricular (BRASIL, 2017c).
}

A partir do Decreto ${ }^{\circ} 9.099$ o nome do PNLD muda para Programa Nacional do Livro e do Material Didático - PNLD. Além da alteração na nomenclatura, outra mudança bastante significativa do novo programa foi a não mais participação das Universidades públicas na avaliação das obras selecionadas, ficando esta ação a cargo de profissionais indicados pelo próprio MEC que possuam licenciatura plena em alguma das disciplinas da educação básica atendidas pelo PNLD e mestrado na área pretendida. Agora também as redes de ensino podem optar pela unificação ou não das obras que serão distribuídas pelo FNDE para o EM, iniciando-se em 2021 e se estendendo até 2022. Essas também deverão informar quais séries serão atendidas e quais obras serão entregues (BRASIL, 2019).

Como pode ser observado, o PNLD está em constante transformação. Entretanto, as ações de aquisição e distribuição seguem uma legislação específica obedecendo às mesmas etapas mostradas na Figura 1

\section{METODOLOGIA}

Este trabalho é de cunho bibliográfico e opinativa, um tipo de pesquisa que proporciona uma reflexão crítica da literatura sobre o tema pesquisado através da elaboração de opinião, uma vez que se faz uma análise dos documentos publicados acerca de determinada temática sem a obrigatoriedade de seguir uma metodologia pré-definida, mas não deixando de resumir, analisar e sintetizar informações referentes ao objeto de estudo (MANCINI; SAMPAIO, 2006.

A questão norteadora para a pesquisa bibliográfica foi: Qual é o impacto da implementação do Novo Ensino Médio na organização e produção dos materiais livros didáticos que serão disponibilizados para o ensino médio a partir do ano de 2021?

Foram utilizadas duas bases de dados para consulta em investigação dos temas da pesquisa Google Acadêmico e SciELO Brasil. Para essa revisão bibliográfica foram utilizados os termos de busca "PNLD" $A N D$ "histórico" $A N D$ "funcionamento" $A N D$ "Novo Ensino Médio".

De início foi feito um levantamento bibliográfico da literatura e dos documentos pertinentes ao tema de estudo deste trabalho. Posteriormente realizou-se a leitura e reflexão acerca do material levantado.

A pesquisa foi estruturada a partir da leitura de artigos e documentos que norteiam a educação no Brasil tais como Resoluções, Decretos, Leis, BNCC e outros materiais de cunho normativo e legal.

\section{RESULTADOS E DISCUSSÃO}

De acordo com o levantamento feito neste estudo percebeu-se que várias mudanças ocorreram quanto à política pública do livro didático desde sua implementação, e também quanto à proposta para o EM no Brasil. Com a lei n'13.415/2017 os currículos passam a ter uma nova organização e é implementado o Novo Ensino Médio, que, segundo o MEC, se justifica por meio dos dados apresentados pela PNAD (Pesquisa Nacional por Amostras Domiciliares ) de 2016 (ver Figura2). 
PROGRAMA NACIONAL DO LIVRO E DO MATERIAL DIDÁTICO (PNLD): UM ESTUDO DE SEU FUNCIONAMENTO E APRESENTAÇÃO DAS MUDANÇAS NOS MATERIAIS À LUZ DO NOVO ENSINO MÉDIO A PARTIR DE 2021

Figura 2: Taxa de frequência bruta à escola conforme os grupos de idade - Brasil.

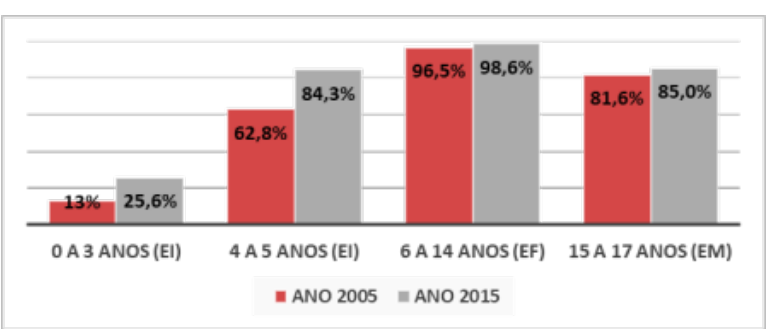

Fonte: Elaborada pelos autores com base em informações levantadas na página do IBGE (2016).

O relatório divulgado mostra que a última etapa da EB é o segmento com maior índice de evasão no Brasil. Esses números apontam para o não atendimento de forma satisfatória do modelo atual de escola.

Nesse sentido, a investigação apontou que um dos problemas que acabam dificultando ainda mais o aprendizado em sala por parte dos jovens e contribuindo para a evasão escolar é o fato que os livros trazem conteúdos generalizados que, muitas vezes, não se aplicam à realidade dos jovens. Assim, não há o desenvolvimento de pensamentos e ações críticas que permitam lidar com situações do cotidiano, limitando o processo de ensino e aprendizagem (TAMANINI; NORONHA, 2019).

Diante do exposto, o EM requer uma nova configuração na qual os interesses dos jovens estejam em harmonia com a oferta da formação escolar. Para o MEC, os currículos devem ser mais adequados às realidades das culturas juvenis e o Novo Ensino Médio deve oferecer uma formação integral, promovendo autonomia e responsabilidade para solucionar problemas reais em sua contemporaneidade através do protagonismo juvenil, estando também mais preparados para o mercado de trabalho. E é importante frisar que quando há melhorias no sistema educacional de um país, consequentemente se observa um crescimento no desenvolvimento socioeconômico deste.

Nessa perspectiva, a pesquisa apontou que os conteúdos escolares passam a ser organizados por áreas do conhecimento, conforme mostra a Tabela 1. Essa nova organização objetiva a abordagem de um mesmo assunto em diferentes disciplinas, estimulando a interdisciplinaridade.

Em síntese, os conteúdos abordados no EM devem agora respeitar as competências gerais da BNCC (1. Conhecimento; 2. Pensamento científico, crítico e criativo; 3. Repertório cultural; 4. Comunicação; 5. Cultural digital; 6. Projeto de Vida e Trabalho; 7. Argumentação; 8. Autoconhecimento e autocuidado; 9. Em- patia e cooperação; e 10. Responsabilidade e cidadania, promovendo educação com equidade e qualidade, garantindo a todos os estudantes brasileiros os mesmos direitos de aprendizagem, conforme traz o texto da BNCC2018 (BRASIL, 2018).

Assim, é necessário que o PNLD altere seus critérios de escolha dos materiais didáticos para que as editoras produzam obras que acompanhem a proposta deste novo documento.

\subsection{Caracterização das obras do PNLD EM 2021}

Segundo a BNCC do EM, as obras do PNLD devem conter elementos relacionados ao protagonismo juvenil, escola que acolhe as juventudes, desafios da sociedade contemporânea, contextualização dos conhecimentos, resolução de problemas da realidade, solução não violenta de conflitos, entre outros. O objetivo é tornar a etapa de ensino que concentra os maiores índices de abandono de estudantes mais atraente e mais próxima da realidade dos discentes.

Os materiais correspondentes ao novo programa que visa concretizar as novas demandas do EM, descritas anteriormente, estão divididos em cinco objetos, como mostra a Figura 3, e serão escolhidos e entregues em duas fases: $1^{\text {a }}$, início em 2020 e distribuição em 2021; $2^{a}$, início em 2021 e distribuição em 2022.

Figura 3: Obras do PNLD do EM 2021.

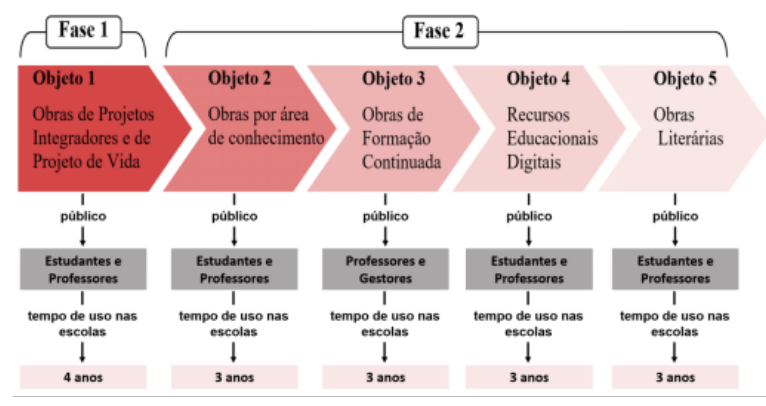

Fonte: Elaborada pelos autores com base em informações levantadas na página do BRASIL (2019).

Com as mudanças, o PNLD teve seu intenção ampliada com a possibilidade de aquisição de outros materiais que servirão de apoio à prática de ensino: obras pedagógicas, softwares e jogos educacionais, materiais de formação continuada para professores e gestores, entre outros.

Além disso, o programa atual conta com outras novidades, como a inclusão de um material didático direcionado aos professores de Educação Física. Mas, em contrapartida, não inclui os materiais de Língua Espanhola. 
PROGRAMA NACIONAL DO LIVRO E DO MATERIAL DIDÁTICO (PNLD): UM ESTUDO DE SEU FUNCIONAMENTO E APRESENTAÇÃO DAS MUDANÇAS NOS MATERIAIS À LUZ DO NOVO ENSINO MÉDIO A PARTIR DE 2021

Tabela 1: Áreas do Conhecimento e Componentes Curriculares do Novo Ensino Médio

\begin{tabular}{ll}
\hline \multicolumn{1}{c}{ Áreas do Conhecimento } & \multicolumn{1}{c}{ Componentes Curriculares } \\
\hline Linguagens e suas Tecnologias & L. Portuguesa, L. Inglesa, Arte e Ed. Física \\
Matemática e suas Tecnologias & Matemática \\
Ciências Humanas e Sociais Aplicadas & Filosofia, Geografia, História e Sociologia \\
Ciências da Natureza e suas Tecnologias & Biologia, Física e Química \\
\hline
\end{tabular}

Fonte: Elaborada pelos autores com base em informações levantadas na página do BRASIL](2018).

\subsubsection{Obras Didáticas de Projetos Integradores}

As obras dos Projetos Integradores devem permitir a ligação entre as áreas do conhecimento por meio de processo de ensino e aprendizagem contextualizado e relevante, priorizando a Competência 7 da BNCC (Argumentação). A aprendizagem contextualizada, ou seja, relacionando os conteúdos com as condições reais inerentes a ações cotidianas do aluno, proporciona aos jovens o desenvolvimento da criatividade para realizar conexões com a realidade, levando-os a refletir sobre vivências na prática social e suas responsabilidades frente a elas. E como fruto dessa aprendizagem, as obras devem conduzir à criação de um produto final que seja significativo para a sociedade. Essas obras incentivam a criatividade, a capacidade de inovação e a autonomia por meio da associação do conhecimento desenvolvido na escola com as necessidades e problemas existentes no entorno dela.

As obras didáticas de Projetos Integradores devem conter seis projetos divididos por área de conhecimento, totalizando 24 projetos para os 3 anos do EM, cada uma contendo 6 (seis) temas, sendo quatro temas obrigatórios para todas as áreas: STEAM (Ciência, Tecnologia, Engenharia, Arte e Matemática), Protagonismo juvenil, Midiaeducação e Mediação de conflitos. E serão compostas por Livro do Estudante impresso, Manual do Professor impresso e Material Digital do Professor (seis videotutoriais).

\subsubsection{Obras de Projeto de Vida}

O material didático de Projeto de Vida se organiza com base nas competências socioemocionais trazidas na BNCC e objetiva desenvolver o protagonismo juvenil. As Competências enfatizadas nessas obras são a 6 (Trabalho e Projeto de Vida) e a 7 (Argumentação). As obras de projetos de vida trazem vivências ligadas à criação e ao fortalecimento de uma escola que acolhe as juventudes, estimulando o desenvolvimento das dimensões pessoal, cidadã e profissional. Através dessas obras será possível trabalhar no aluno o autoconhecimento, sua formação para convivência, ética, cidadania, autoconfiança e resiliência. Assim, será possível formar adultos mais preparados para o mundo e seus desafios, sejam eles profissionais ou pessoais.

A obra didática de Projeto de Vida será composta pelo Livro do Estudante impresso (volume único), Manual do Professor impresso e Material Digital do Professor (três videotutoriais).

\subsubsection{Obras Didáticas por Áreas do Conhecimento e Obras Específicas}

As obras didáticas por área de conhecimento devem ser organizadas em seis volumes não sequenciais que devem abordar todas as Competências Gerais e Específicas e Habilidades de cada área do conhecimento, permitindo uma maior interdisciplinaridade na qual os conhecimentos são adquiridos a partir da agregação entre as disciplinas, sem excluí-las apesar das peculiaridades. Entretanto, é preciso estar atento à essa organização por área do conhecimento, pois a flexibilização do currículo pode causar uma desigualdade no aprendizado, acirrando ainda mais as desigualdades educacionais.

O material será composto pelo livro do estudante impresso, material didático do estudante, manual do professor impresso e material digital do professor (videotutorial por volume e coletânea de áudios para a área de Linguagens e suas Tecnologias).

As obras didáticas específicas atenderão as áreas de Língua Portuguesa, Língua Inglesa e Ciências Humanas e Sociais Aplicadas em diálogo com a Matemática. Esses materiais serão compostos pelo Livro do Estudante impresso, Material Digital do Estudante (apenas para Língua Inglesa), Manual do Professor impresso e Material Digital do Professor (videotutorial e coletânea de áudios de Língua Inglesa).

\subsubsection{Obras de Formação Continuada}

As obras de formação continuada serão destinadas a professores e gestores. Cada componente dessas esferas receberá um volume correspondente a sua área e um vídeo tutorial conforme mostra a tabela 2 .

Esse material é de suma importância por possibilitar 
PROGRAMA NACIONAL DO LIVRO E DO MATERIAL DIDÁTICO (PNLD): UM ESTUDO DE SEU FUNCIONAMENTO E APRESENTAÇÃO DAS MUDANÇAS NOS MATERIAIS À LUZ DO NOVO ENSINO MÉDIO A PARTIR DE 2021

aos profissionais da educação uma oportunidade de diminuir as defasagens de sua formação inicial e de aprofundar os seus conhecimentos objetivando a melhoria e o desenvolvimento das mais variadas formas didáticas e metodológicas, contribuindo para a retirada do aluno do lugar de mero expectador, passando a ser sujeito ativo no processo educacional.

\subsubsection{Recursos Educacionais Digitais}

Esses materiais servirão de suporte aos professores para que possam trabalhar os conteúdos de forma mais leve e mais próxima à realidade tecnológica das novas gerações, fugindo um pouco das aulas tradicionais expositivas. Tais ferramentas contribuirão certamente para um melhor aprendizado.

Os Recursos Educacionais Digitais estarão organizados por coleção e divididos em duas categorias: 1 Recursos Educacionais Digitais das Aéreas do Conhecimento/Especialidades; e 2 - Recursos Educacionais Digitais dos Temas Integradores. As coleções de ambas as categorias são compostas por Manual do Professor Digital, Videoaulas, Propostas de Instrumentos Pedagógicos e Itens de Avaliação Resolvidos e Comentados.

Vale ressaltar que os recursos digitais não devem ser protagonistas e sim servirem de apoio pedagógico e elemento facilitador para que a educação escolar seja efetiva.

\subsubsection{Obras Literárias}

Um hábito de grande contribuição para a aprendizagem do ser humano é a leitura, pois favorece o aprendizado por meio da aquisição de novos conhecimentos e visões de mundo diferenciadas, amplia a capacidade cognitiva para compreensão de ideias e organização de pensamento, enriquece o vocabulário e estimula a capacidade de argumentação. Frente a todos esses benefícios, as obras literárias vêm para somar no processo de formação dos jovens.

As obras literárias contemplam a Língua Portuguesa e Inglesa e são compostas pelo Livro do Estudante impresso, Material Digital do Estudante (videotutorial), Manual do Professor impresso (constituído por livro impresso com conteúdo igual ao livro do estudante) e Material Digital do Professor (PDF e videotutorial).

\section{CONSIDERAÇÕES FINAIS}

Percebeu-se ao longo deste estudo que a política pública do LD sofreu várias mudanças desde a sua criação, objetivando-se melhorar a produção dos materiais através do aprimoramento das características técnicas e das avaliações, e também buscando universalizar a distribuição. Mudanças essas que são de grande importância uma vez que o LD, recurso pedagógico mais utilizado na escola, possibilita ao aluno ter acesso a muitas informações e auxilia o professor em sala de aula no processo de ensino-aprendizagem.

A análise dos dados revelou que o PNLD é um dos maiores programas em investimento e atendimento do mundo e que trará novas obras que objetivam desenvolver no aluno um protagonismo juvenil, adequando a escola às necessidades contemporâneas, promovendo uma formação integral que contemple as mais amplas competências.

Ressalta-se ainda que as mudanças trouxeram pontos positivos, como a inclusão de livro didático para Educação Física, sendo esta uma demanda antiga dos professoras desta área. O programa também traz novos tipos de materiais como, por exemplo, recursos digitais mais elaborados e amplos que modernizam e oferecem aos profissionais da educação mais ferramentas pedagógicas. Outro ponto positivo que merece destaque e que foi reconhecido por alguns profissionais da educação nos artigos investigados é o número significativo de materiais didáticos.

Entretanto, é importante destacar alguns pontos negativos como a retirada das obras de Língua Espanhola, ficando a cargo das instituições ofertarem ou não a disciplina. Outro ponto negativo é a exclusão das Universidades Públicas do processo de avaliação dos materiais didáticos. Instituições estas que são reconhecidas pela capacidade formadora de professores. A avaliação passa a ser feita agora por profissionais escolhidos pelo MEC.

Além disso, a ampliação do tempo de uso dos materiais de 3 para 4 anos passa a ser questionada diante da desatualização das informações trazidas e da dificuldade de conservação dos mesmos.

Ainda sobre os materiais didáticos, não fica claro no documento do PNLD a produção de objetos destinados a alunos portadores de necessidades especiais. Exemplificando, não se observa em nenhum momento a preocupação específica do MEC em produzir materiais em Libras (Língua Brasileira de Sinais), excluindo os deficientes auditivos do processo formativo.

Outro aspecto bastante relevante é a visão do atual Governo sobre os LDs. Em alguns meios de comunicação o presidente afirmou que os livros didáticos possuem "muita coisa escrita" e que é preciso "suavizálos" (MAZIEIRO, 2020). Há uma tentativa de suprimir diversos princípios éticos e democráticos, que contrariam as próprias diretrizes do PNLD, e de direcionar as metodologias de educação a partir de uma perspectiva 
PROGRAMA NACIONAL DO LIVRO E DO MATERIAL DIDÁTICO (PNLD): UM ESTUDO DE SEU FUNCIONAMENTO E APRESENTAÇÃO DAS MUDANÇAS NOS MATERIAIS À LUZ DO NOVO ENSINO MÉDIO A PARTIR DE 2021

Tabela 2: Composição das obras de formação continuada

\begin{tabular}{lll}
\hline \multirow{2}{*}{ Obras de Formação Continuada } & Volumes & $\begin{array}{l}\text { Videotutorial } \\
\text { por volume }\end{array}$ \\
\cline { 2 - 3 } & Quantidade & Quantidade \\
\hline $\begin{array}{l}\text { Equipe gestora (diretores, vice-diretores, coordenadores } \\
\text { pedagógicos, supervisores, chefes de secretaria etc.) }\end{array}$ & 1 & 1 \\
$\begin{array}{l}\text { Língua Portuguesa, Inglês, Educação Física, Música, Teatro, } \\
\begin{array}{l}\text { Dança, Artes Visuais (Linguagens e suas tecnologias) } \\
\text { Matemática (Matemática e suas Tecnologias, com enfoque }\end{array}\end{array}$ & 7 & 1 \\
$\begin{array}{l}\text { em pensamento computacional) } \\
\text { Biologia, Física e Química (Ciências da Natureza e suas } \\
\text { Tecnologias) }\end{array}$ & 1 & 1 \\
$\begin{array}{l}\text { Filosofia, Geografia, História, Sociologia (Ciências } \\
\text { Humanas e Sociais Aplicadas) }\end{array}$ & 4 & 1 \\
\hline
\end{tabular}

Fonte: Elaborada pelos autores com base em informações levantadas na página do BRASIL(2018).

política, chegando a negar aos estudantes o acesso às informações.

O PNLD necessita sim estar sempre passando por mudanças para se tornar cada vez mais uma política bem estruturada que consegue atender ao seu objetivo maior: distribuir materiais didáticos às instituições públicas de EB. Mas também é importante lembrar que os professores exercem um papel importantíssimo na escolha desses materiais e em alguns artigos foi possível perceber a insatisfação por parte de alguns de não existir uma total clareza de como e quando os materiais serão escolhidos e distribuídos para uso.

Agora as obras devem seguir as Competências e Habilidades da BNCC que buscam promover o desenvolvimento integral dos estudantes, contemplando não só a formação intelectual, mas também social, emocional e cultural através de vivências mais próximas às suas realidades, a fim de preparar o aluno para solucionar questões do cotidiano e atuar no mundo do trabalho, exercendo a cidadania de forma plena. É importante salientar que os livros e materiais didáticos continuam sendo um dos principais objetos pedagógicos e que a correta abordagem dos conteúdos, mais próximas às realidades dos alunos, pode contribuir para a diminuição das taxas de evasão escolar, um dos grandes desafios enfrentados hoje no EM.

Este estudo também apresenta algumas limitações que devem ser consideradas em trabalhos futuros: a quantidade de artigos encontrados para investigação e também algumas questões de pesquisa que podem ser exploradas para fornecer informações importantes a respeito, por exemplo, da visão dos profissionais da educação quanto aos novos materiais disponibilizados para uso no EM.

\section{REFERÊNCIAS}

BRAGANÇA, A. As políticas públicas para o livro e a leitura no brasil: o instituto nacional do livro (1937-1967). Matrizes, Universidade de São Paulo, v. 2 , n. 2, p. 221-246, 2009. ISSN 1982-2073.

BRASIL. Constituição da República Federativa do Brasil. Brasília: Centro Gráfico, 1988. Disponível em: $<$ http://www.planalto.gov.br/ccivil_03/constituicao/ constituicao.htm> Acesso em: 08 abr. 2021.

Lei de Diretrizes e Bases da Educação Nacional, LDB. 9394/1996. 1996.

Decreto $\mathrm{n}^{\circ}$ 9099, de 18 de julho de 2017. Regulamenta no âmbito federal, dispositivos da Lei $n^{\circ}$ da Lei n ${ }^{\circ}$ 9.394, de 20 de dezembro de 1996, que dispõe sobre sobre o Programa Nacional do Livro e do Material Didático. Diário Oficial da União, Poder Executivo, Brasília, DF, 18 jul. 2017. - Seção 1, p. 7 Diário Oficial da União - Seção 1 - 20/8/1985, Página 12178. 2017.

Fundo Nacional de Desenvolvimento da Educação. PNLD 2017. 2017.

Lei de Diretrizes e Bases da Educação Nacional. Lei ${ }^{0} \mathbf{1 3 . 4 1 5 / 2 0 1 7}$, de 13 de fevereiro de 2017, Altera as Leis nos 9.394, de 20 de dezembro de 1996, que estabelece as diretrizes e bases da educação nacional, e 11.494, de 20 de junho 2007, que regulamenta o Fundo de Manutenção e Desenvolvimento da Educação Básica e de Valorização dos Profissionais da Educação, a Consolidação das Leis do Trabalho - CLT, aprovada pelo Decreto-Lei no 5.452, de 10 de maio de 1943, 
PROGRAMA NACIONAL DO LIVRO E DO MATERIAL DIDÁTICO (PNLD): UM ESTUDO DE SEU FUNCIONAMENTO E APRESENTAÇÃO DAS MUDANÇAS NOS MATERIAIS À LUZ DO NOVO ENSINO MÉDIO A PARTIR DE 2021

e o Decreto-Lei no 236, de 28 de fevereiro de 1967; revoga a Lei no 11.161, de 5 de agosto de 2005; e institui a Política de Fomento à Implementação de Escolas de Ensino Médio em Tempo Integral. 2017. 2017.

Base Nacional Comum Curricular: ensino médio. Brasília: Ministério da Educação, 2018. Disponível em: $<$ http://basenacionalcomum.mec.gov. br/> Acesso em: 08 abr. 2021. 2019.

PNLD Conectado 2021 - Novo Ensino Médio.

CASSIANO, C. C. Mercado de livro didático no Brasil.[on-line] I Seminário Brasileiro sobre Livro e História Editorial. 1. ed. Rio de Janeiro: Universidade Federal Fluminense, 2004.

DI GIORGI, C. A. G.; MILITÃO, S. C. N.; MILITÃO, A. N.; PERBONI, F.; RAMOS, R. C.; LIMA, V. M. M.; LEITE, Y. U. F. Uma proposta de aperfeiçoamento do pnld como política pública: o livro didático como capital cultural do aluno/família. Ensaio: avaliação e políticas públicas em educação, SciELO Brasil, v. 22, n. 85, p. 1027-1056, 2014.

FNDE. Histórico. 2021. Disponível em:

<http://www.fnde.gov.br/component/k2/item/

518-hist\%C3\%B3rico> Acesso em: 15 mar. 2021.

Programas do Livro. 2021. Disponível

em: <https://www.fnde.gov.br/index.php/ programas/programas-do-livro/legislacao/item/ 9787-sobre-os-programas-dolivro> Acesso em: 15 mar. 2021

FREITAS, N. K.; RODRIGUES, M. H. O livro didático ao longo do tempo: a forma do conteúdo. DAPesquisa, v. 3 , n. 5 , p. 300-307, 2019.

IBGE. Resultado dos Dados Preliminares

do Censo - 2016. 2016. Disponível em: $<$ https://www.ibge.gov.br/np_download/novoportal/ documentos_institucionais/Plano_de_Dados_Abertos_ IBGE_2016_2017_20160831.pdf> Acesso em: 10 mar. 2021

MACIEL, G. N. O programa nacional do livro didático e as mudanças nos processos de avaliação dos livros de geografia. PESQUISAR-Revista de Estudos e Pesquisas em Ensino de Geografia, v. 1, n. 1, p. 231-253, 2014.

MANCINI, M. C.; SAMPAIO, R. F. Quando o objeto de estudo é a literatura: estudos de revisão. Rev. bras. 